\title{
MECANISMOS DE ABSORÇÃO DE AMINOÁCIDOS E OLIGOPEPTÍDIOS. Controle e implicações na dietoterapia humana ${ }^{+}$
}

\author{
Patrícia Baston FRENHANI* e Roberto Carlos BURINI**
}

RESUMO - Os mecanismos envolvidos na absorção de aminoácidos e di-tripeptídios são revistos direcionadamente às implicações na nutrição humana. As membranas borda em escova e basolateral são atravessadas por aminoácidos e ditripeptídios mediante mecanismos passivos (difusão simples ou facilitada) ou ativos (co-transportadores de $\mathrm{Na}^{+}$ou $\mathrm{H}^{+}$). O sistema ativo dependente de $\mathrm{Na}^{+}$ocorre principalmente na borda em escova e a difusão simples na basolateral. Ambas as membranas apresentam o transporte passivo facilitado. Os aminoácidos livres usam tanto o sistema passivo, como o ativo, enquanto os di-tripeptídios utilizam mais o sistema ativo $\left(\mathrm{H}^{+}\right)$. A borda em escova possui sistemas distintos para aminoácidos livres e di-tripeptídios, com os primeiros utilizando preferentemente o $\mathrm{Na}^{+}$-dependente e os demais o $\mathrm{H}^{+}$dependente. Os aminoácidos livres são transportados em diferentes velocidades por carreadores, em mecanismos saturáveis e competitivos, com especificidade para aminoácidos básicos, ácidos e neutros. Os di e tripeptídios têm pelo menos dois carreadores, ambos $H^{+}$dependentes. Na membrana basolateral os aminoácidos livres são transportados por difusão simples enquanto os di-tripeptídios o são ativamente por processo de troca aniônica. A principal regulação do transporte transmembrana de aminoácidos e di-tripeptídios é a concentração desses substratos ao nível da membrana. Afora isso, di e tripeptídios são mais eficientemente absorvidos que os aminoácidos livres os quais por sua vez o são melhor que os tetra ou mais peptídios. Desta forma, o di-tripeptídios resultam em maior retenção nitrogenada que os demais e são particularmente úteis nos casos de redução da capacidade absortiva intestinal. Os peptídios não absorvidos são fermentados pelas bactérias colônicas resultando ácidos graxos de cadeia curta, ácidos dicarboxílicos, compostos fenólicos e amônia. Os ácidos graxos e a amônia são fixados pelas bactérias para produção de energia e aminoácidos, respectivamente.

DESCRITORES - Proteínas, metabolismo. Peptídios, metabolismo. Absorção intestinal. Dieta.

Centro de Metabolismo e Nutrição (CeMeNutri) da Faculdade de Medicina da Universidade Estadual Paulista - UNESP, Botucatu, SP. Nutricionista. Aluna (doutorado) do Curso de Pós-Graduação em Ciência dos Alimentos (área de concentração: Nutrição Experimental) da Faculdade de Ciências Farmacêuticas da Universidade de São Paulo, São Paulo, SP.

** Professor Titular do Departamento de Clínica Médica da Faculdade de Medicina da UNESP. Coordenador do CeMeNutri.

Endereço para correspondência: Dr. Roberto Carlos Burini - Centro de Metabolismo e Nutrição - Faculdade de Medicina de Botucatu - UNESP

- Caixa Postal 584 - 18618-970 - Botucatu, SP. 


\section{INTRODUÇÃO}

As proteínas ingeridas não sofrem na boca, modificações químicas, sendo apenas reduzidas a partículas menores. No estômago, as proteínas e polipeptídios são desnaturados por ação do $\mathrm{HCl}$ e hidrolisadas pela pepsina. A digestão no estômago representa apenas $10-20 \%$ da digestão total protéica. A maior parte desta digestão ocorre no lúmen do duodeno e jejuno, sob a influência do suco pancreático, processando-se, quase completamente no íleo terminal. No intestino delgado, a enteropeptidase, em $\mathrm{pH}$ neutro, ativa o tripsinogênio a tripsina que, por sua vez, promove a ativação das outras propeptidases do suco pancreático. Ocorre, então, a hidrólise luminal de proteínas e polipeptídios, produzindo aminoácidos (AA) livres e pequenos peptídios (2-6 AA). Os AA e pequenos peptídios, produtos da hidrólise luminal, são então hidrolisados pelas peptidases da borda em escova a AA, di e tripeptídios que são absorvidos, principalmente, no jejuno proximal ${ }^{(10)}$.

\section{Fases da Absorção}

\section{Mecanismos de absorção de aminoáci- dos e peptídios}

A absorção dos produtos da digestão protéica, AA, di e tripeptídios, ocorre por processos complementares, podendo ser transportados por três mecanismos ${ }^{(14,19)}$ (Fig. 1):

a) transferência passiva por difusão simples;

b) transferência passiva por difusão facilitada;

c) transferência ativa por co-transporte.

A transferência passiva pode ser por vias celulares ou paracelulares, enquanto a transferência ativa, por vias celulares ${ }^{(14)}$ (Fig. 2).

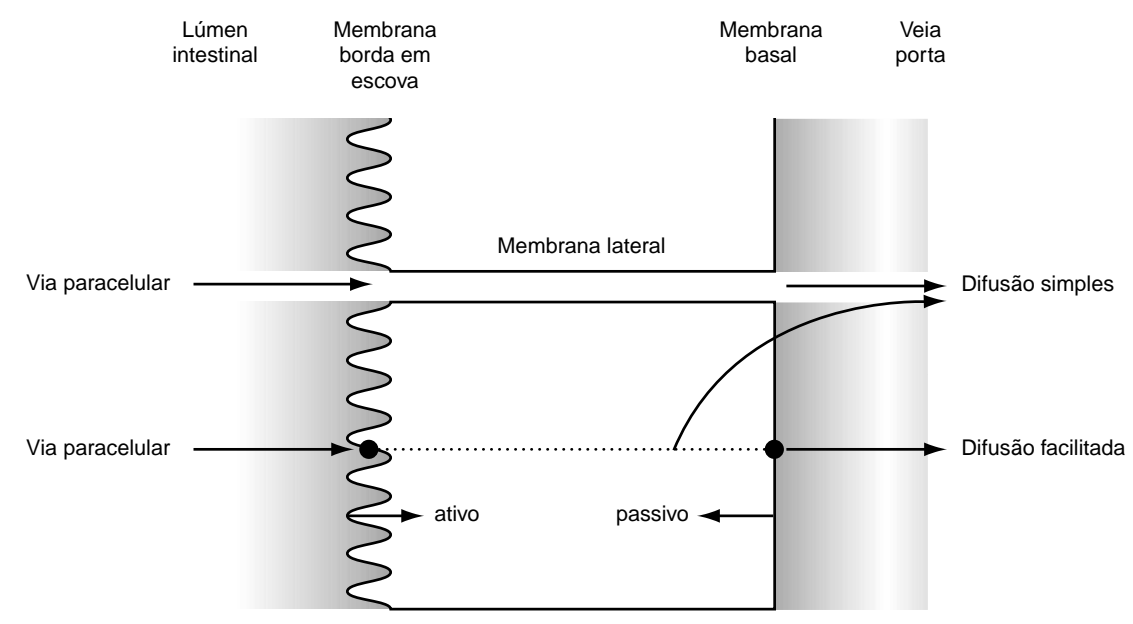

Figura 1 - Vias de absorção de aminoácidos e peptídios

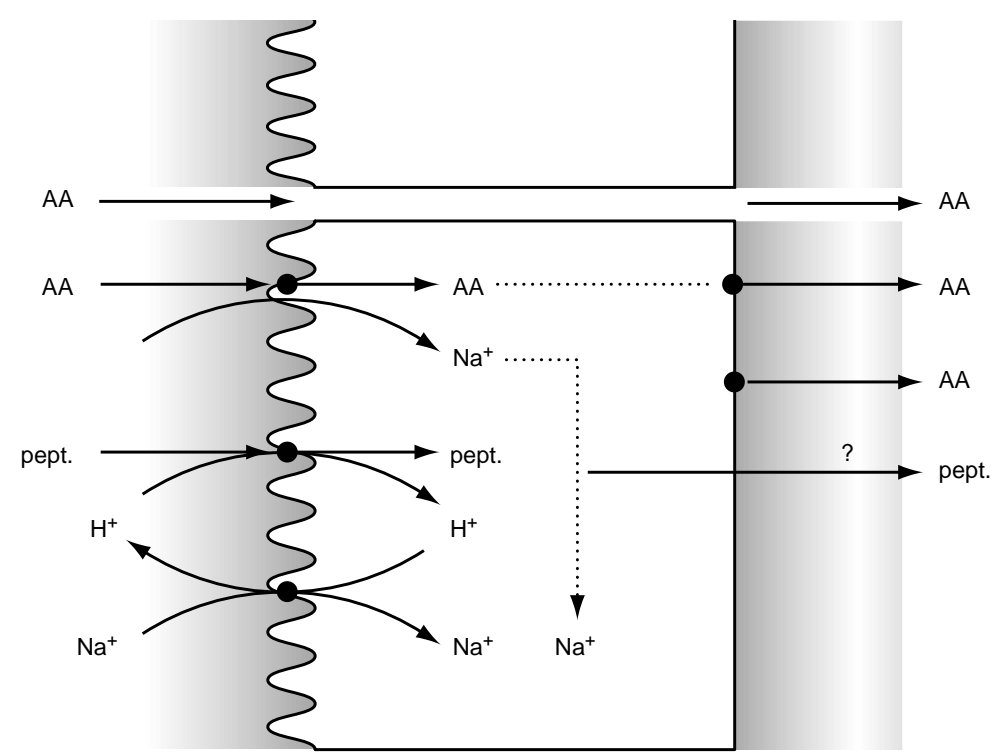

Figura 2 - Mecanismos de transferência mucosa/serosa de aminoácidos e peptídios

A transferência passiva por difusão simples, ocorre principalmente com AA livres e é inversamente proporcional à hidrofilia e diretamente proporcional ao gradiente de concentração do AA, ou seja, quanto mais hidrofóbico for o AA (maioria dos neutros) e quanto maior for seu gradiente de concen- tração através da membrana, maior será a importância da transferência por difusão simples $^{(19)}$. Os di e tripeptídios também podem ser transportados por um mecanismo passivo paracelular, o que, porém, parece não ser importante por ocorrer em pequena quantidade $^{(14)}$. 
A transferência passiva é importante para equilibrar a concentração de AA transportados através da membrana ${ }^{(20)}$. Desta forma, quando há aumento da concentração intracelular de AA decorrente da absorção, ocorre o aparecimento do gradiente de concentração do AA em relação ao sangue, responsável pela sua difusão para a veia porta.

A transferência passiva por difusão facilitada ocorre também, principalmente com AA livres, porém esse transporte é mais rápido por ser mediado por carreadores, independentes de sódio $\left(\mathrm{Na}^{+}\right)$e da energia metabólica. Sua importância também é a de equilibrar a concentração de AA, no citoplasma e no líquido extracelular, transportados através da membrana ${ }^{(20)}$.

A transferência ativa por co-transporte ocorre com os AA livres, di e tripeptídios (Fig. 2). É mediada por carreadores, porém é capaz de "bombear" uma substância contra gradiente de concentração (ou potencial eletroquímico) e, portanto, com gasto energético $^{(20)}$. A energia é obtida de modo indireto por meio do gradiente eletroquímico de íon que seja ativamente transportado. Por isso são chamados de co-transportes: os AA livres são co-transportados juntamente com $\mathrm{Na}^{+}, \mathrm{e}$ seu transporte depende do gradiente eletroquímico de $\mathrm{Na}^{+}$gerado pelo transporte ativo primário $\mathrm{Na}^{+}-\mathrm{K}^{+}$-ATPase na membrana basolateral, sendo chamado de transporte ativo secundário ${ }^{(9,14,19,20)}$ (Fig. 3). Os di e tripeptídios são co-transportados juntamente com prótons $\left(\mathrm{H}^{+}\right)$e seus transportes dependem do gradiente eletroquímico de $\mathrm{H}^{+}$, que é gerado e mantido pelo contra-transporte Na-prótons na membrana borda em escova em resposta ao gradiente de $\mathrm{Na}^{+}$, sendo chamado de transporte ativo terciário ${ }^{(1,8,9,11,14)}$.

Os carreadores de AA apresentam sítios de ligação para moléculas de $\mathrm{AA}$ e para $\mathrm{Na}^{+}$, e têm a finalidade de aumentar a afinidade do AA pelo sistema transportador, sem afetar a velocidade máxima ${ }^{(9,11)}$. Esse fato pode ser relevante em situações onde as concentrações dos AA são baixas ${ }^{(9)}$. Quando os dois sítios estão carregados, o carreador dirige-se para o interior da célula movido pelo gradiente de $\mathrm{Na}^{+}$, transportando consigo o AA, que será captado no espaço intracelular.

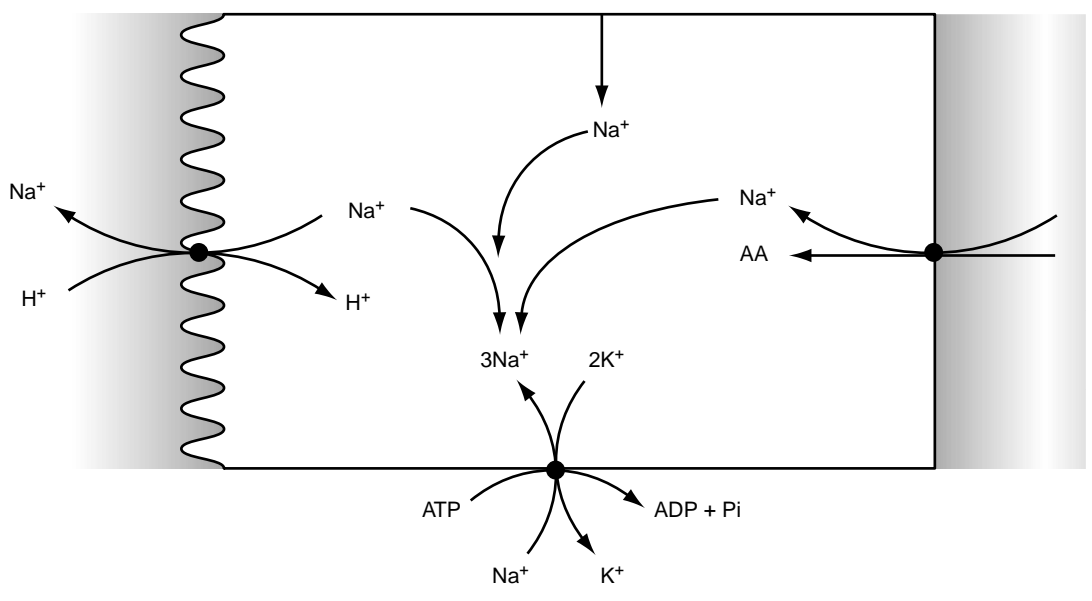

Figura 3 - Gradiente $\mathrm{Na}^{+} / \mathrm{H}^{+} / \mathrm{K}^{+}$no enterócito
A importância do transporte ativo reside no fato de que é o mecanismo quantitativamente mais eficiente e predominante, e é o principal mecanismo para absorção de di e tripeptídios ${ }^{(19,20)}$.

O transporte celular de AA e peptídios pode ocorrer através das membranas borda em escova e basolateral, que apresentam propriedades diferentes de transporte tanto para os AA, quanto para os peptídios ${ }^{(1)}$.

Os principais locais de assimilação protéica ocorrem no duodeno e jejuno proximal $^{(13,25)}$, sendo que pequenas quantidades alcançam o íleo terminal, onde ocorre a quase completa digestão e absorção das proteínas.

\section{Transporte de aminoácidos}

a) Membrana borda em escova

O sistema de transporte de AA através da borda em escova apresenta as seguintes características $^{(3,9,19,20)}$ :

- é saturável, pois depende de carreadores;

- possui velocidade de absorção específica para cada AA, de acordo com a afinidade pelos carreadores;

- há múltiplos sistemas transportadores, específicos para AA neutros, básicos e ácidos, que podem se diferenciar dependendo:

- do meio e substratos;

- da dependência ou não do gradiente de $\mathrm{Na}^{+}$(eletrogênico ou não) e

- da diferença de potencial da membrana; 
- alguns AA apresentam afinidade por mais de um sistema carreador, como é o caso da glicina;

- há competição para um mesmo carreador entre moléculas estruturalmente relacionadas. Assim, a absorção de alguns AA pode ser inibida por outros, como, por exemplo, o triptofano inibe a absorção de histidina e a leucina diminui a absorção de isoleucina, fenilalanina e triptofano ${ }^{(4)}$;

- há diferenças de velocidade de absorção entre os isômeros de AA (sistema estereoespecífico), sendo que o isômero natural Lé absorvido mais rapidamente por transporte ativo dependente de vitamina B6, do que o isômero D, por ser transportado passivamente por difusão simples;

- os AA são absorvidos através dessa membrana, principalmente por transporte ativo $\mathrm{Na}^{+}$-dependente.

b) Membrana basolateral

O transporte de AA na membrana basolateral se difere da membrana borda em escova nos seguintes aspectos ${ }^{(19)}$ :

- é um sistema diferente do sistema de transporte da membrana da borda em escova, pois a membrana basolateral apresenta outros transportadores que também dependem ou não de $\mathrm{Na}^{+}$;

- por ser mais permeável aos AA que a membrana borda em escova, a difusão simples nesta membrana é uma via mais importante, principalmente para os AA hidrofóbicos;

- o principal mecanismo de transporte ocorre passivamente por difusão facilitada.
Assim, os mecanismos para transporte de AA podem ser:

- $\mathrm{Na}^{+}$dependente (transporte ativo), ocorrendo principalmente na membrana borda em escova;

- $\mathrm{Na}^{+}$independente (transporte passivo facilitado), ocorrendo tanto na borda em escova, como na membrana basolateral, e

- difusão simples, ocorrendo principalmente na membrana basolateral e vias paracelulares.

c) Sistemas de transporte

Os diferentes sistemas de transporte de AA podem ser classificados de acordo com a afinidade dos mesmos pelos carreadores.

Assim, temos na membrana borda em escova $^{(14,19)}$ (Fig. 4):

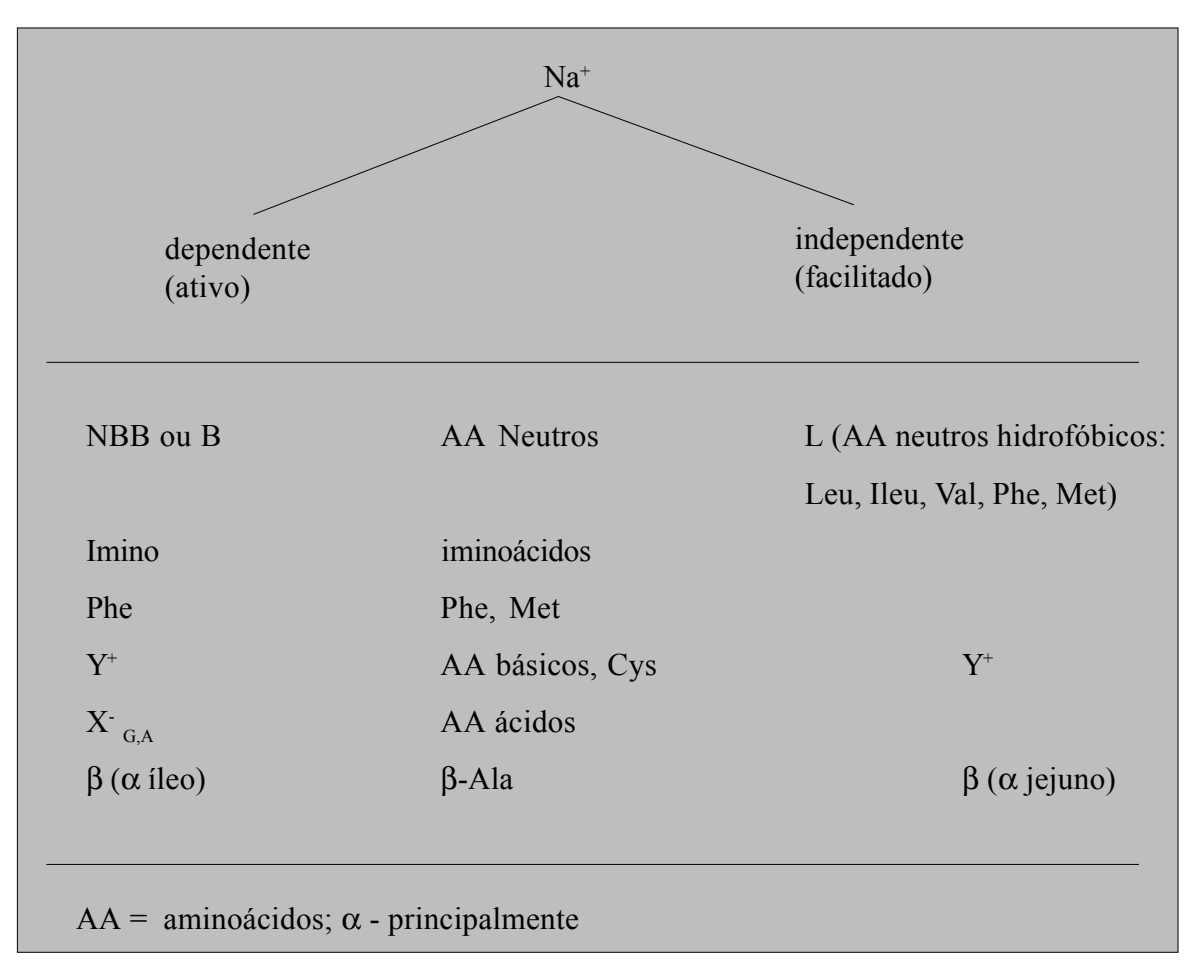

Figura 4 - Sistemas transportadores de aminoácidos na borda em escova do enterócito

1) Sistemas $\mathrm{Na}^{+}$-dependente (ativo):

- NBB ou B: sistema borda em escova neutra, específico para a maioria dos AA neutros, tanto hidrofóbicos quanto hidrofílicos;

- IMINO: específico para os iminoácidos;

- PHE: transporta fenilalanina e metionina;

- $\mathrm{Y}^{+}$: transporta AA básicos e cisteína;

- X-G,A: transporta AA ácidos: glutâmico e aspártico;

- b: transporta b-alanina (principalmente no íleo).

Os sistemas de transporte IMINO e XG,A podem não ser importantes fisiolo- 
gicamente, já que a maioria desses AA são transportados como di e tripeptídios ${ }^{(12)}$.

2) Sistemas $\mathrm{Na}^{+}$-independente (facilitado):

- $\mathrm{y}^{+}$: específico para os AA básicos e cisteína. É denominado de y minúsculo para diferenciar do sistema $\mathrm{Na}^{+}$ dependente.

- L: específico para a maioria dos AA neutros, principalmente os hidrofóbicos, como a leucina, isoleucina, valina, fenilalanina e metionina;

- b: transporta b-alanina (principalmente no jejuno).

Na membrana basolateral, também tem$\mathrm{se}^{(14,19)}$ (Fig. 5):
1) Sistemas $\mathrm{Na}^{+}$-dependente (ativo). Desempenha papel importante em suprir as células absortivas intestinais com AA para própria nutrição celular, durante períodos entre refeições, uma vez que a orientação desse sistema é do sangue para as células intestinais:

- A: específico para AA polares, ou seja, hidrofílicos, de cadeia curta, como a alanina;

- ASC: transporta AA neutros, como a alanina, serina e cisteína;

- N: transporta os ácidos glutâmico e aspártico e a histidina.

2) Sistemas $\mathrm{Na}^{+}$-independente (facilitado). É semelhante ao sistema da borda em escova, apresentando:

- $\mathrm{y}^{+}$: transporta AA básicos e cisteína;

- L: transporta a maioria dos AA neutros, principalmente os hidrofóbicos, como a leucina;

- asc: transporta os AA neutros, como a alanina, serina, cisteína e triptofano, denominado de asc minúsculo para diferenciar do sistema $\mathrm{Na}+$ dependente.

\section{Transporte de di e tripeptídios}

a) Membrana borda em escova

O transporte de di e tripeptídios através da membrana borda em escova apresenta as seguintes características ${ }^{(1,2,3,9,14,19,21)}$.

- é específico para di e tripeptídios, sendo independente e distinto do sistema de transporte de AA, não havendo competição entre peptídios e AA, apenas entre peptídios;

- o sistema de transporte possui pouca afinidade para tetra ou mais peptídios, que são hidrolisados pelas peptidases da borda em escova a AA, di e tripeptídios;

- é estereoespecífico, ou seja, prefere os peptídios dos L-AA fisiológicos;

- pode haver mais de uma via para o transporte de di e tripeptídios, pois a absorção de carnosina é inibida por muitos di e tripeptídios, como a glipro, mas não é afetada por lisil-lisina ou glutamil-glutâmico;

AA = aminoácidos

AA neutros hidrofóbicos

L

(Leu) $\mathrm{y}^{+}$ 
- apresenta maior afinidade para os peptídios de AA com cadeias laterais grandes e hidrofóbicas;

- a velocidade de transporte de AA de uma solução de di ou tripeptídios é mais rápida e mais eficiente do que a de uma solução equivalente de AA livres. Assim, a quantidade total de cada AA que é absorvido sob a forma de di e tripeptídios, é consideravelmente maior que a quantidade absorvida sob a forma de AA livre;

- o transporte de dipeptídios é tão eficiente que sua absorção supera sua hidrólise pelas peptidases da borda em escova, as quais apresentam baixa atividade para dipeptídios, (menos que $12 \%$ da atividade celular total) ${ }^{(27)}$;

- o transporte é dependente de prótons $(\mathrm{H}+)$, pois é estimulado pelo gradiente de $\mathrm{pH}$ através da membrana da borda em escova.

Sistemas de transporte

Recentes estudos moleculares demonstraram que pelo menos dois carreadores de di e tripeptídios podem ser encontrados na borda em escova mas, até o momento, o número e especificidades de substratos são desconhecidos ${ }^{(1,7,8)}$. Esses transportadores:

- são eletrogênicos (acoplados ao $\left.\mathrm{H}^{+}\right)$;

- estão associados à acidificação intracelular;

- são independentes dos íons $\mathrm{Na}^{+}, \mathrm{K}^{+} \mathrm{e}$ $\mathrm{Cl}^{-}$extracelulares, e

- independentes do potencial de membrana.

Os dois transportadores isolados (clonados por expressão) foram chamados $\mathrm{de}^{(1,7,8) \text { : }}$
1) PepT1, cujo mRNA foi isolado do intestino, rim, fígado e cérebro do coelho, sugerindo que há mecanismos comuns envolvidos no transporte endógeno e exógeno de peptídios. Foi fortemente expressado no jejuno, no duodeno e no íleo, mas não no cólon;

2) e HPT1, cujo cDNA foi isolado do trato gastrointestinal (duodeno, jejuno, íleo, cólon e ductos pancreáticos), porém ausente no rim, fígado e pulmão. Não apresenta seqüência homóloga com PepT1.

O carreador PepT1 constitui o principal mecanismo para a absorção intestinal de quaisquer di e tripeptídios, contendo AA ácidos, básicos ou hidrofóbicos, porém apresenta maior afinidade por peptídios com cadeias laterais alifáticas e grandes ${ }^{(8)}$.

b) Membrana basolateral

Quanto ao transporte de peptídios através da membrana basolateral, pouco se tem investigado, mas parece claro que é diferente do encontrado na borda em escova ${ }^{(1)}$. Parece ser processo eletroneutro, ao contrário da borda em escova; está associado a troca de ânions, possibilitando um contra-transporte; e sua base molecular ainda é desconhecida.

Resumindo os principais mecanismos de transporte de AA e peptídios através das membranas borda em escova e basolateral, da mucosa intestinal, tem-se que:

- os peptídios neutros podem ser absorvidos intactos acoplados ao íon $\mathrm{H}^{+}$, ou podem ser hidrolisados rapidamente pelas peptidases da borda em escova, principalmente se um AA neutro está localizado na posição amino-terminal, a AA livres neutros, que se unem ao "pool" de AA neutros na superfície da borda em escova;

- esses AA neutros podem ser transportados ativamente acoplados ao $\mathrm{Na}^{+}$ ou podem ser aborvidos por difusão simples ou facilitada sem gasto energético;

- os peptídios neutros absorvidos intactos são, então, hidrolisados pelas peptidases citosólicas a AA livres, unindo-se ao "pool" de AA neutros intracelular (Fig. 6). Estes AA são, então, transportados para a veia porta,

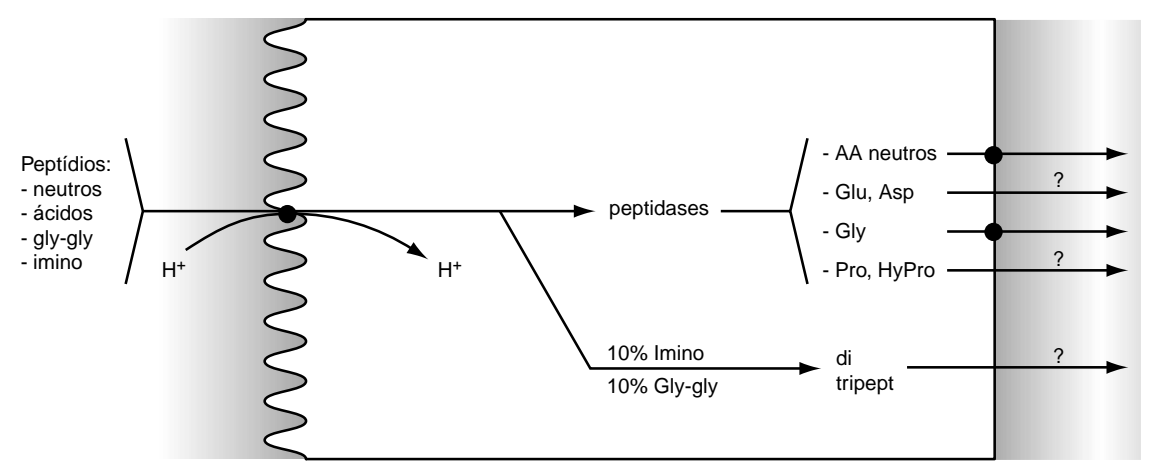

Figura 6 - Transferência de peptídios no enterócito 
ativamente acoplados ao $\mathrm{Na}^{+}$ou principalmente por transporte passivo (difusão simples ou facilitada);

- os AA livres básicos podem ser transportados ativamente acoplados ao $\mathrm{Na}^{+}$ou passivamente por difusão simples ou facilitada, tanto na borda em escova, quanto na basolateral, sendo que na basolateral o transporte passivo é predominante;

- os peptídios iminoácidos e os peptídios de glicina, anserina e carnosina, são absorvidos, principalmente intactos, acoplados ao íon $\mathrm{H}^{+}$por ausência de peptidases específicas da borda em escova. Esses peptídios são 90\% hidrolisados pelas peptidases citosólicas a AA prolina, hidroxiprolina e glicina, e os $10 \%$ restantes são transportados pela membrana basolateral sob a forma de di e tripeptídios por um mecanismo desconhecido (Fig. 6). O transporte na basolateral dos AA livres prolina, hidroxiprolina e glicina, produtos da hidrólise intracelular, ocorre, principalmente, por transporte passivo;

- os peptídios ácidos também são absorvidos, principalmente intactos, acoplados ao $\mathrm{H}^{+}$e são, então, hidrolisados pelas peptidases ácidas citosólicas a ácidos glutâmico e aspártico que são transportados através da membrana basolateral por difusão simples ou, principalmente, por um sistema de transporte ativo acoplado ao $\mathrm{Na}^{+}$(Fig. 6).

Assim, apenas os AA neutros e básicos são quantitativamente transportados como AA livres. Os iminoácidos, glicina, ácidos dicarboxílicos, anserina e carnosina, são transportados como constituintes de pequenos peptídios ${ }^{(12)}$.
Uma mistura de peptídios contendo tipos diferentes de AA pode utilizar mais que um mecanismo de transporte, dependendo de sua afinidade relativa para os sistemas hidrolíticos da borda em escova ou para o transporte celular específico ${ }^{(12)}$.

O transporte de $\mathrm{Na}^{+}, \mathrm{H}^{+}$e $\mathrm{Cl}^{-}$na borda em escova é feito segundo o gradiente eletroquímico $^{(20)}$ (Fig. 3). O gradiente de potencial eletroquímico de $\mathrm{Na}^{+}$, essencial para energizar o transporte ativo de AA, é gerado pela bomba $\mathrm{Na}^{+} / \mathrm{K}^{+}$na membrana basolateral (um transporte ativo primário que utiliza energia do ATP para "bombear" o $\mathrm{Na}^{+}$do meio intracelular para o extracelular $)^{(11,20)}$. Esse gradiente de $\mathrm{Na}^{+}$promove o contra-transporte $\mathrm{Na}^{+}-\mathrm{H}^{+}$na borda em escova que, por sua vez, gera o gradiente de $\mathrm{H}^{+}$, essencial para energizar o transporte de peptídios.

A maioria do $\mathrm{N}$-amínico no sangue pósprandial está na forma de AA livres ${ }^{(3,21)}$. Dentre os raros peptídios encontrados no sangue portal, estão aqueles contendo prolina e hidroxiprolina (vistos após ingestão de gelatina) e carnosina e anserina (observados após a ingestão de certos tipos de carne, principalmente peito de frango).

\section{Moduladores dos processos absortivos}

A atividade dos transportadores de AA e peptídios na borda em escova, é regulada pelos respectivos níveis de substratos ${ }^{(16)}$, sendo que as variações que ocorrem nessa atividade, dependem do custo da síntese dos transportadores e da disponibilidade de nutriente no lúmen, cuja presença causa estimulação da atividade do transportador.

Portanto, a absorção não parece ser diretamente regulada por mecanismos neurais ou endócrinos, como os processos digestivos, dependendo apenas da presença dos produtos a serem absorvidos em contato com a superfície da mucosa $a^{(3)}$.

\section{Eficiência da absorção de aminoácidos livres, di e tripeptídios}

Quanto à eficiência da absorção de AA livres, di e tripeptídios, sabe-se que esses são mais eficientemente absorvido do que AA livres que, por sua vez, são mais absorvidos do que os oligopeptídios (tetra ou mais). Isso ocorre devido aos seguintes fatores (3, 9, 13, 21, 23, 25).

- enquanto os AA livres parecem ser mais rapidamente absorvidos apenas no delgado proximal, os di e tripeptídios o são tanto na porção proximal, quanto distal do delgado;

- em quantidades equivalentes de ditripeptídios e misturas de AA livres, os di-tripeptídios apresentam velocidade de absorção mais rápida (10 vezes maior);

- alguns AA livres competem pelo mesmo carreador, havendo inibição da absorção;

- o transporte de AA livres é facilmente saturável, diminuindo a velocidade de absorção;

- os di e tripeptídios apresentam absorção mais rápida do que tetra ou mais peptídios, pois estes necessitam ser hidrolisados pelas peptidases da borda em escova a AA e ditripeptídios, para serem absorvidos, o que limita sua captação intestinal.

- a aborção de peptídios é mais resistente aos efeitos de alterações alimentares que a aborção de AA, pois a desnutrição protéico-energética reduz a aborção jejunal de leucina sem afetar a absorção de gli-leu ${ }^{(21)}$;

- o transporte de peptídios possibilita a conservação de energia metabólica, pela 
habilidade de transportar vários AA através da membrana pelo mesmo custo em energia que é necessária para transportar um único $\mathrm{AA}^{(22)}$.

Essas considerações sobre os processos digestivos e absortivos de proteínas são importantes para escolha da forma de oferta do nitrogênio para indivíduos com função intestinal prejudicada ${ }^{(13)}$.

\section{Eficiência do Aproveitamento}

A oferta alimentar das fontes de nitrogênio pode ser feita por meio de dietas: (1) polimérica, que contém proteína integral não digerida; (2) oligomérica ou hidrolisado protéico, que contém pequenos peptídios, e (3) elementar, que contém AA livres.

Estudos em humanos comparando a eficiência do aproveitamento dessas dietas, demonstraram que:

- quando hidrolisado protéico contendo $62 \%$ de oligopeptídios, ou seja, tetra ou mais peptídios, foi comparado com proteína integral em indivíduos com alteração moderada da função gastrointestinal (pancreatite compensada, gastrectomia parcial BI, doença de Crohn ileocolônica com ressecção do íleo terminal, retocolite ulcerativa com colectomia total, diverticulose jejunal e trauma do duodeno) alimentados por sonda nasogástrica ou jejunostomia, $\mathrm{o}$ balanço nitrogenado entre as duas dietas foi semelhante. Isso sugere que não há vantagens da administração de tetra ou mais peptídios sobre a proteína integral nestes tipos de pacientes, pois a hidrólise dos oligopeptídios na borda em escova pode ser fator limitante para

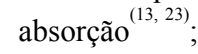

- Quando AA livres foram comparados com proteína integral, em indivíduos desnutridos, porém com função intestinal normal (pacientes neurológicos, neurocirúrgicos, pré e pósoperatório, com anorexia nervosa, meningite, tuberculose), alimentados por sonda nasogástrica, o balanço nitrogenado entre as duas dietas foi semelhante, indicando que estes tipos de pacientes com função intestinal normal não se beneficiam com AA livres, além de serem mais caros, hiperosmóticos e menos palatáveis ${ }^{(18)}$;

- Quando hidrolisado protéico, contendo principalmente di e tripeptídios(63\%), foi comparado com proteína integral em indivíduos com síndrome do intestino curto (SIC) com jejunostomia alta, alimentados por nutrição enteral total, o balanço nitrogenado da dieta com di e tripeptídios foi maior do que com proteína integral $^{(5)}$;

- quando hidrolisado protéico contendo também di e tripeptídios foi comparado com AA livres em pacientes com prejuízo grave da função gastrointestinal (SIC, insuficiência pancreática grave por fibrose cística), em estudos de perfusão intestinal, a absorção de di e tripeptídios foi maior do que o equivalente de AA livres ${ }^{(24,26)}$.

Portanto di e tripeptídios apresentam maior eficiência do aproveitamento (melhor retenção de nitrogênio) do que proteína integral e AA livres, em indivíduos com prejuízo grave da função gastrointestinal, seja por perda significante da superfície absortiva (ressecção do intestino delgado, doença celíaca) ou por perda da função digestiva (pancreatectomia, insuficiência pancreática grave) ${ }^{(13)}$, além de serem melhor tolerados (menor osmolaridade), diminuindo a tendência a diarréia e vômito.

Em várias condições patológicas, como a doença celíaca, a absorção de AA é mais gravemente afetada que a de peptídios. $\mathrm{Na}$ desnutrição protéico-energética, como a induzida por jejunostomia, a aborção jejunal de AA livres é reduzida, mas a absorção de dipeptídios não é afetada ${ }^{(21,27)}$.

\section{Considerações importantes em dietética}

Como se pode observar nos estudos citados acima, os hidrolisados protéicos disponíveis comercialmente se diferenciam em relação à composição de seus peptídios, ou seja, uns contém maior quantidade de di e tripeptídios e outros, de oligopeptídios.

A eficiência absortiva dos peptídios desses hidrolisados em relação aos AA livres, depende: (1) da composição em AA e a seqüência dos mesmos (define os sítios de hidrólise pelas enzimas pancreáticas) na proteína de origem do hidrolisado; (2) do método de hidrólise; (3) e do grau de hidrólise ${ }^{(9)}$.

Assim, cada hidrolisado é diferente em termos de composição, extensão de hidrólise, composição dos peptídios constituintes e AA livres $^{(9)}$.

As indicações para o uso de di e tripeptídios são:

- em situações onde há diminuição da capacidade absortiva do intestino por prejuízo da função gastrointestinal, como por exemplo:

- na desnutrição protéica energética, principalmente secundária à má digestão ou má absorção;

- em pancreatectomizados;

- em indivíduos com SIC;

- doença celíaca 
- situações onde a absorção de di e tripeptídios é menos afetada que a dos AA livres, além de ser menos hiper-

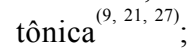

- e na insuficiência pancreática, por fibrose cística por exemplo, onde os indivíduos toleram melhor além dos di e tripeptídios, os oligopeptídios também, pois as enzimas da borda em escova, neste caso não estão alteradas, sendo eficientes para hidrolisar os peptídios de até seis $\mathrm{AA}^{(21)}$.

- em doenças onde há defeitos primários no transporte intestinal de AA livres, como $^{(9,25)}$ :

- a cistinúria, onde há defeito no transporte de AA básicos mais a cisteína;

- e doença de Hartnup, onde há defeito genético alterando o mecanismo de transporte de AA neutros, principalmente o triptofano e a fenilalanina.
Nestas doenças, a necessidade protéica pode ser suprida na forma de di e tripeptídios, não ocorrendo normalmente sinais clínicos de desnutrição protéica ${ }^{(27)}$.

\section{Excreção fecal de nitrogênio}

Os processos de digestão e absorção protéicos são muito efícientes, pois do total da proteína diária a ser digerida, representada por cerca de 70-100 g de proteína exógena (dietética) e cerca de 35-200 g de proteína endógena (enzimas digestivas, células descamadas), apenas aproximadamente 6-12 g de proteína por dia são perdidas nas fezes (1-2 g nitrogênio) ${ }^{(6,15)}$.

O mecanismo de excreção fecal de nitrogênio, ocorre da seguinte maneira:

- as proteínas e peptídios não absorvidos pelo intestino delgado, juntamente com outros componentes da fibra alimentar, são digeridas e fermentadas pelas bactérias do cólon, a ácidos graxos de cadeia curta, ácidos dicarboxílicos, compostos fenólicos e amônia, que podem ser absorvidos ou metabolizados pelo intestino grosso ${ }^{(13)}$.

- as bactérias geralmente utilizam a amônia como sua fonte preferencial de nitrogênio ${ }^{(17)}$. A energia necessária para a fixação pelas bactérias desse nitrogênio da amônia, é obtida por meio de ácidos graxos de cadeia curta, produtos da fermentação bacteriana das fibras alimentares. O restante da amônia não utilizada por elas ou é excretada com as fezes, juntamente com massa bacteriana, ou é reabsorvida pelos colonócitos, de onde parte para o fígado onde será metabolizado e convertido em uréia. Essa uréia será eliminada na urina ou sofrerá novamente a ação bacteriana no cólon (nitrogênio derivado da uréia plasmática representa cerca de $10 \%$ do nitrogênio fecal total), por meio de uma urease, transformando-se em amônia e fechando o ciclo.

Assim, o nitrogênio pode ser retido ou pela fixação no fígado da amônia, ou pela absorção intestinal dos AA, ambos derivados da ação das bactérias ${ }^{(17)}$. 
Frenhani PB, Burini RC. Mechanisms of amino acids and oligopeptides absorption in humans. Arq Gastroenterol, São Paulo, 36(4):227237, 1999.

ABSTRACT - The mechanisms involved in the absorption of amino acids and oligopeptides are reviewed regarding their implications in human feedings. Brush border and basolateral membranes are crossed by amino acids and di-tripeptides by passive (facilitated or simple diffusion) or active ( $\mathrm{Na}^{+}$or $\mathrm{H}^{+}$co-transporters) pathways. Active $\mathrm{Na}^{+}$-dependent system accurs mainly at brush border and simple diffusion at basolateral, both membranes have the passive facilitated transport. Free-amino acids use either passive or active transport systems whereas di-tripeptides do mainly active ( $H^{+}$co-transporter). Brush border have distinctive transport system for amino acids and di-tripeptides. The former occurs mainly by active $\mathrm{Na}^{+}$dependently whereas the later is active $\mathrm{H}^{+}$-dependent with little affinity for tetra or higher peptides. Free amino acids are transported at different speed by saturable, competitive carriers with specificity for basic, acidic or neutral amino acids. Di and tripeptides have at least two carriers both electrogenic and $H^{+}$-dependent. The basolateral membrane transport of amino acids is mostly by facilitated diffusion while for di-tripeptides it is an active anion exchange associated process. The main regulation of amino acids and di-tripeptide transport is the presence o substrate at the mucosal membrane with higher the substrate higher the absorption. Di and tripeptides are more efficiently absorbed than free amino acids which in turns are better absorbed than oligopeptides. So di-tripeptides result in better $N$-retention and is particularly useful in cases of lower intestinal absorption capacity. The non-absorbed peptides are digested and fermented by colonic bacteria resulting short-chain fatty acids, dicarboxylic acids, phenolic compounds and ammonia. Short-chain fatty acid provides energy for colonocytes and bacteria and the ammonia not fixed by bacteria returns to the liver for ureagenesis.

HEADINGS - Proteins, metabolism. Peptides, metabolism. Intestinal absorption. Diet.

\section{REFERÊNCIAS BIBLIOGRÁFICAS}

1. Boyd CAR. Intestinal oligopeptide transport. Proc Nutr Soc, 54:519, 1995.

2. Brandsch M, Miyamoto Y, Ganapathy V, Leidach FH. Expression and protein Kinase $\mathrm{C}$-dependent regulation of peptide/H+ cotransport system in the Caco-2 human colon carcinoma cell line. Biochem J, 299:253, 1994.

3. Burini RC, Campana AO. Digestão, absorção, circulação e utilização de nutrientes. In: Riella MC, ed. Suporte nutricional parenteral e enteral. Rio de Janeiro, Guanabara Koogan, 1993. p.137-65.

4. Chaves N. Estudo químico-fisiológico das proteínas. In: Chaves N, ed. Nutrição básica e aplicada. Rio de Janeiro, Guanabara Koogan, 1985. p.71.

5. Cosnes J, Evard D, Beaugerie L, Gendre JP, Lequintrec Y. Improvement in protein absorption with a small-peptide based diet in patients with high jejunostomy. Nutrition, 8:406, 1992.

6. Crim MC, Munro HN. Proteins and amino acids. In: Shils ME, Olson JA, Shike M, ed. Modern nutrition in health and disease. Malvern, Lea \& Febiger, 1994. p.3-35.
7. Dantzig AH, Hoskins J, Tabas LB, Bright S, Shepard RL, Jenkins K, Duckworth DC, Sportsman JR, Mackensen D, Rosteck PRJ, Skatrup PL. Association of intestinal peptide transport with a protein related to the cadferin superfamily. Science, 264:430, 1994.

8. Fei YJ, Kanai Y, Nussberger S, Ganapathy V, Leibach FH, Romero MF, Singh SK, Boron WF, Hedger MA. Expression cloning of a mammalian proton-coupled oligopeptide transporter. Nature, 368:563, 1994.

9. Freitas O, Dos Santos JE, Dutra de Oliveira JE. Bases bioquímicas do suporte nutricional enteral. Arch Latino Am Nutr, 45:84, 1995.

10. Frenhani PB, Burini RC. Mecanismos de ação e controle da digestão de proteínas e peptídios em humanos. Arq Gastroenterol, 36:139, 1999.

11. Ganapathy V, Leibach FH. Is intestinal peptide transport energized by a proton gradient? Am J Physiol, 249:G153, 1985.

12. Gray GM, Cooper HL. Protein digestion and absorption. Gastroenterology, 61:535, 1971.

13. Grimble GK, Silk DB. Peptides in human nutrition. Nutr Res Rev, 2:87, 1989. 
14. Hirst BH. Dietary regulation of intestinal nutrient carriers. Proc Nutr Soc, 52:315, 1993.

15. Hopfer U. Digestion and absorption of basic nutritional constituents. In: Devlin TM, ed. Textbook of Biochemistry. New York, Wiley Medical, 1986. p.909-40.

16. Inoue Y, Espat NJ, Frohnapple DJ, Epstein H, Copeland EM, Souba WW. Effect of total parenteral nutrition on amino acid and glucose transport by the human small intestine. Ann Surg, 217:604, 1993.

17. Jackson AA. Sahvage of urea-nitrogen and protein requirements. Proc Nutr Soc, 54:535, 1995.

18. Jones BJM, Silk DBA. Comparison of an elemental and polymeric enteral diet in patients with normal gastrointestinal function. Gut, 24:78, 1983.

19. Kutchai HC. Digestão e absorção. In: Berne RM, Levy MN, ed. Fisiologia. Rio de Janeiro, Guanabara, 1990. p.572-89.

20. Kutchai HC. Membranas celulares e o transporte transmembrana de solutos e de água. In: Berne RM, Levy MN, ed. Fisiologia. Rio de Janeiro, Guanabara, 1990. p.5-18.
21. Matthews DM, Adibi SA. Peptide absorption. Gastroenterology, 71:151, 1976.

22. Matthews DM. Absorption of peptides. In: Matthews DM, ed. Protein absorption: development and present state of the subject. New York, Wiley-Liss, 1991. p.235-319.

23. Rees RG, Grimble GK, Silk DBA. Do patients with moderately impaired gastrointestinal function requiring enteral nutrition need a predigested nitrogen source? A prospective crossover controlled clinical trial. Gut, 33:877, 1992.

24. Silk DB, Fairclough PD, Clark ML, Hegarty JE, Marris TC, Addison JM, Burston D, Clegg KM, Mattews DM. Use of a peptide rather than a free amino acid nitrogen source in chemically defined "elemental" diets. JPEN J Parenter Enteral Nutr, 4:548, 1980.

25. Silk DBA, Grimble GK, Rees RG. Protein digestion and aminoacid and peptide absorption. Proc Nutr Soc, 44:63, 1985.

26. Silk DBA. Towards the optimization of enteral nutrition. Clin Nutr, 6:61, 1987.

27. Sleisenger MH, Kim YS. Protein digestion and absorption. N Engl J Med, 300:659, 1979. 